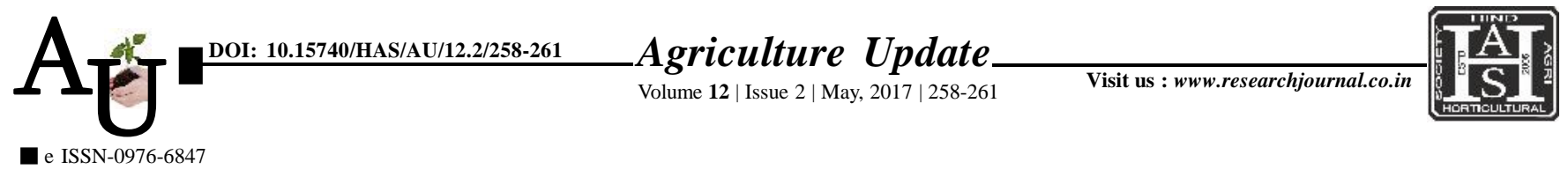

\title{
Rеsearch автісle: : Effectiveness of NAIP in augmenting the farmers' adoption regarding irrigation water management interventions for wheat cultivation in Banswara district
}

\author{
SANTOSH DEVI SAMOTA, F.L. SHARMA, RAM LAL KHATIK AND SUNITA \\ KUMARI
}

Article Chronicle: Received :

09.03.2017;

Revised :

24.03.2017;

Accepted :

06.04.2017

KEY WORDS :

NAIP, IWM,

Beneficiaries, Non -

beneficiaries,

Adoption

Author for correspondence :

\section{SANTOSH DEVI SAMOTA}

Department of

Extension Education,

Rajasthan College of

Agriculture, UDAIPUR (RAJASTHAN) INDIA

See end of the article for authors' affiliations
SUMMARY : The present research paper is based on the formative evaluation of NAIP with special reference to irrigation water management in wheat cultivation in Banswara district of Southern Rajasthan. The consortia project of NAIP was executed disadvantaged NAIP in four tribal districts namely, Udaipur, Banswara, Dungarpur and Sirohi. Banswara district was selected for the investigation based on maximum households covered under the project. In Banswara district there are four Panchayat Samities viz., Talwara, Ghatol, Garhi and Kushalgarh. Talwara Panchayat Samiti was selected for the study. One Panchayat Samiti viz., Talwara was selected for the study. In Telwara Panchayat Samiti four Gram Panchayat viz., Talwara, Ghatol, Garhi and Kushalgarh were taken as such, for the present study and considered as beneficiaries. For the comparison between beneficiaries and non-beneficiaries farmers four Gram Panchayat were considered for the sample study. This sample of 19 beneficiaries each from every beneficiary village and similar size of sample of non-beneficiaries (19) from each of the nonbeneficiary villages constituted total size of sample i.e. 152. Alarming findings indicated that almost similar number of beneficiaries (Bs) and non-beneficiaries (NBs) fell under higher level of adoption about irrigation water management (IWM) in wheat. Adverse impact of NAIP with regards to IWM interventions introduced was noticed since, beneficiaries respondents $50(65.79 \%)$ expressed slightly higher adoption of IWM as compared with those of non- beneficiaries $42(55.27 \%)$. Data also show that $16(21.06 \%)$ beneficiaries and $30(39.47 \%)$ non-beneficiaries belonged to medium level of adoption of IWM. Furthermore, that is booting, tillering and milking stages at first priority (MPS $85.65 \%$ ) followed by irrigation in crop at CRI stage (tillering and flowering stages) ranked as second (MPS 82.15). At the same time it was also observed that out of seven intervention of IWM, the beneficiaries farmers visualized comparatively more adoption of IWM sub intervention viz., irrigation after 21 days of sowing, irrigation at CRI and flowering stages and providing at least $450-650 \mathrm{~mm}$ irrigation water in wheat crop.

How to cite this article : Samota, Santosh Devi, Sharma, F.L., Khatik, Ram Lal and Kumari, Sunita (2017). Effectiveness of NAIP in augmenting the farmers' adoption regarding irrigation water management interventions for wheat cultivation in Banswara district. Agric. Update, 12(2): 258-261; DOI : 10.15740/HAS/AU/12.2/258261. 